\title{
Pharmacokinetic Properties and Safety of Cadmium- Containing Quantum Dots as Drug Delivery Systems
}

\author{
Lourdes Rodriguez-Fragoso, \\ Ivonne Gutiérrez-Sancha, \\ Patricia Rodríguez-Fragoso, \\ Anahí Rodríguez-López and Jorge Reyes-Esparza \\ Additional information is available at the end of the chapter \\ http://dx.doi.org/10.5772/58553
}

\section{Introduction}

The pharmaceutical industry's current challenge to serve public health needs by has become increasingly difficult due to obstacles that slow down the process of identifying and developing new treatments of unmet medical diseases. There are many auspicious new therapies that have progressed into clinical trials in recent years; they include treatments for cancer, inflammation, neurodegenerative and psychiatric disorders, anti-infective respiratory and metabolic disorders, but their development has failed for a number of reasons. Overcoming these obstacles incurs tremendous costs and takes a lot of time; new therapies must then be identified get successfully issued into the marketplace. In response, government, academic and pharmaceutical industry researchers are looking for new ways to approach the discovery of new medicines and technologies that will not only combat illness but also improve the quality of life, a most important outcome of expensive new treatments. Counterbalancing this important goal are efforts to innovate in the face of increasing public pressure to control costs and increase the speed with which new medicines arrive on the marketplace.

For a few years now, nanotechnology has emerged as an area of science and technology that is leading us to a new industrial revolution. Nanotechnology is defined as scientific and technological development at the atomic and molecular levels, in the range of about 1-100 nm, to obtain a fundamental understanding of phenomena and materials on a nanoscale and to create and use structures, devices and systems that have novel properties and functions due 
to their size. The most interesting aspect of nanotechnology is its ability to work with materials of small size that, however, can change radically on a physical and chemical level at this scale: electrical conductivity, color, resistance or elasticity, among other properties, behave differently than they do in volumetric material. The emergence of nanotechnology in the health sciences has led to a new discipline called nanomedicine, the main objective of which is the development of tools to diagnose, prevent and treat diseases when they are still not very advanced or incipient [1].

Nanomedicine includes three main areas: nanodiagnosis, nanotherapy and regenerative medicine [2]. Their main goals are explained in the following paragraphs:

a) The purpose of nanodiagnosis is to identify diseases in their initial stages at the cellular or molecular level and, ideally, down to the level of a single cell, using contrast nanodevices and systems [3]. Early identification would lead to immediate application of appropriate treatment, increasing the probability of healing. Nanosystem diagnostics can be used in vitro or in vivo. In vivo diagnosis normally requires that devices penetrate the human body to identify and (ideally) quantify the presence of specific pathogen or cancer cells, for example. This entails a number of problems associated with the biocompatibility of the material of the device, as well as sophisticated design to ensure effectiveness and minimize side effects. Meanwhile, the in vitro diagnosis provides greater design flexibility of design because it can be applied to very small samples of body fluids or tissue from which specific detection can be performed (pathogens or genetic defects, for example) in a very short time with high precision and sensitivity [4]. Because of these fundamental differences, in vitro detection using nanoscale devices is expected to reach the market faster and consolidate more easily than in vivo methods. There are two main areas of work: images and nanosystems and biosensors. These systems rely on the use of nanoparticles, semiconductors, or magnetic metals, such as contrast agents for in vivo labeling. These new systems can increase sensitivity and give better contrast in imaging techniques. One of the first proposed nanoparticle systems was the identification of tumor cells. In the case of nanodiagnostics, the main testing devices being developed are nanobiosensors, devices capable of detecting in real time without the need for fluorescent or radioactive markers and with high sensitivity and selectivity all kinds of chemical and biological substances [5].

b) The aim of nanotherapy is to drive nanosystems containing recognition elements to act or transport and release drugs exclusively in cells or affected areas in order to achieve a more effective treatment, minimizing side effects [6]. Approximately $40 \%$ of the novel new molecules (NNMs) selected for full-scale development based on their safety and efficacy data fail to reach the clinical development phase due to poor biopharmaceutical properties, which translate into poor bioavailability and undesirable pharmacokinetic properties. Several nanotechnologybased products, including Doxil® (doxorubicin $\mathrm{HCl}$ liposome injection) and Abraxane ${ }^{\circledR}$ (paclitaxel protein-bound particles for injectable suspension) are already on the market $[7,8]$. In addition, Baxter and Elan are promoting Nanoedge ${ }^{\circledR}$ dispersion technology and Nano-

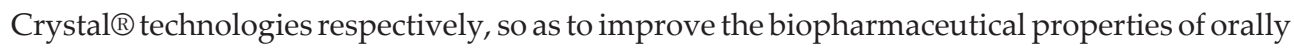


administered therapeutic agents [9]. Nanotechnology can play an important role in the development of proper formulations that address the drug delivery issues related to NNMs with poor biopharmaceutical properties, such as poor solubility, poor permeability across the intestinal epithelium, enzymatic or nonenzymatic degradation/metabolism, complexation with chelating ligands or metal cations, intestinal efflux, and poor transport properties. Additionally, nanotechnology can also achieve desirable pharmacokinetic and toxicological properties that aid in the accelerated development of the NNM. Nanoparticulate drug delivery systems are being used to alter the drug's biopharmaceutics and pharmacokinetics such as drug absorption, distribution, metabolism, and elimination [10]. Examples of nanoscale delivery systems include polymeric nanoparticles, liposomes, nanoemulsions, micelles, and dendrimers.

A number of nano-delivery systems are designed to encapsulate the drug in carriers (e.g., liposomes, micelles, polymeric nanoparticles, and dendrimers), which masks the unfavorable biopharmaceutical properties of the molecule and replaces them with the properties of the materials used to make the nano-delivery system. These approaches were used for a number of poorly soluble NNMs in aqueous phase or easily degraded and metabolized NNMs. Another approach involves the covalent conjugation of the molecules with carrier and targeting moieties (e.g., polymer-drug conjugate, antibody-drug conjugates, solubilizers-drug conjugates, etc.) that override the drug's poor biopharmaceutical properties and improve the pharmacokinetics and biodistribution. This approach was used for site-specific or targeted delivery to alter the pharmacokinetics of the drug by increasing the plasma elimination halflife, preventing degradation or metabolism of the drug in the systemic circulation, and possibly altering the organ and subcellular distribution of the drug, thus alleviating unwanted toxicity due to nonspecific distribution, improving patient compliance and providing favorable clinical outcomes [11]. Advances in nanomedicine are also applied for site-specific drug and gene delivery strategies, especially for the treatment of cancer and other life-threatening diseases $[12,13]$. The nanotechnology approach, although expensive and time consuming, can significantly assist in the accelerated development of NNMs with adequate druglike properties and can assist the pharmaceutical companies in adding more lead molecules to their pipeline. One of the major challenges in this process is the development of "nanotherapies", specifically those targeting diseased tissues and organs while avoiding damage to surrounding healthy cells and, thus, the dreaded side effects of current treatments.

c) Regenerative medicine aims to repair or replace damaged tissues and organs using nanotechnology tools [14]. Regenerative nanomedicine deals with the repair or replacement of damaged or diseased tissues and organs by applying methods derived from gene therapy, cell therapy, chemical dosage and bio-regenerative tissue engineering, stimulating the human body's very own repair mechanisms [15]. The main contributions of nanotechnology to regenerative medicine are related to the production of new materials and support systems, the use of embryonic and adult stem cells, and the production of bioactive molecules that serve as signals for cell differentiation [16]. Nanotechnology can play a dominant role in tissue engineering by facilitating new materials and techniques that allow fro more efficient tissue 
integration and the ability to generate microenvironment parts that are particularly conducive to tissue regeneration. The main difficulty lies in finding suitable materials that allow for the fabrication of structures that remain active while the affected organ regenerates the damaged area [17]. Some of the materials that are being used include carbon nanotubes, the nanoparticles as hydroxyapatite or zirconia particles, biodegradable polymer nanofibers, nanocomposites, etc. One of the greatest achievements is the development of biomaterials with the ability to mimic the extracellular matrix, forming a real support identical to what appears naturally in cells and on which stem cells can be grown for subsequent implant in patients to repair or replace damaged organs.

The enormous advances in nanotechnology during the past decades have allowed for substantial developments in the field of health sciences. The systems and methods described are only selected examples of the enormous activity that is taking place in thousands of laboratories around the world to improve health and quality of life across the whole of society. In the present chapter, we discuss the pharmacokinetic properties and safety of cadmium-containing quantum dots as tools for diagnosis and drug delivery systems.

\section{Quantum dots in medical science}

Quantum dots (QDs) have aroused much interest in recent years, especially in view of their potential applications in biology and medicine [18]. This heterogeneous class of engineered nanoparticles that are both semiconductors and fluorophores is rapidly emerging as an important type of nanoparticles with numerous potential applications in medicine [19]. QDs are semiconductor inorganic nanomaterials ranging from 1-10 $\mathrm{nm}$. They contain elements found in groups II-IV (e.g., CdSe, CdTe, CdS, and ZnSe) or III-V (eg, InP and InAs) of the periodic table. QDs have fluorescent properties that offer superior features to conventional organic dyes, including high quantum yield, broad absorption, and narrow emission spectra (Figure 1). QDs are more photostable than conventional fluorophores; e.g., it has been reported that, under the same excitation conditions, $90 \%$ of the fluorescence of a normal organic dye fades within 1 minute, whereas the fluorescence of QDs remains intact even after 30 minute or more [20].

In terms of their basic structure, QDs consist of an inorganic core, an inorganic shell and aqueous organic coating. The size of the inorganic core determines the wavelength (color) of light emitted following excitation (Figure 1). The inorganic shell is responsible for increasing the photostability and luminescent properties of the QDs [21]. The photo stability of the inorganic shell has allowed QDs to be used as probes for imaging cells and tissues over long spans of time. While there are many useful features to QDs, there are also a number of issues related to their structure and function [22]. One of the most problematic is a phenomenon known as "blinking". This is the term used to describe the alternation between the lightemitting and -non-emitting state of the QD. This factor limits the number of photons that can be detected in a given time period and it also contributes to unpredictable photon arrival 
(a)

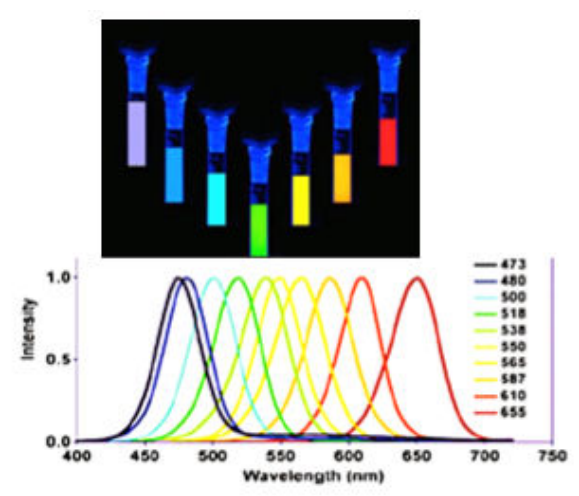

(b)

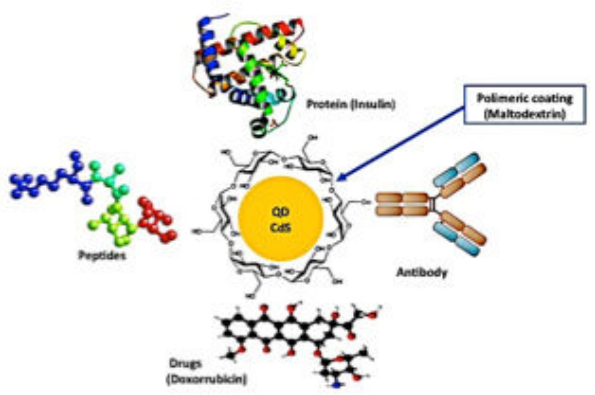

Figure 1. Spectrum and basic structure of quantum dots. (a) Emission spectra of quantum dots; (b) Schematic structure of quantum dots and conjugation to biomolecules.

times. It has been proposed that this feature of QDs could be suppressed by "passivating" the QDs' surface with thiol moieties, polymers, or by using the QDs in free suspension. A standard nomenclature is generally utilized to describe the component parts of various QDs: Core/Shell or Core/Shell-Conjugate. For example, a QD with a cadmium-sulfide core and a maltodextrin shell which has been protein conjugated would be designated as CdS/protein [23]. As fluorescent particles, quantum dots can be detected and tracked with the same approach developed for organic fluorophores. All the technical development has been directly transposed to QD imaging and tracking. Biomedical applications exploit the fluorescent properties of QDs, particularly their advantage over traditional organic dyes for both diagnostic and clinical applications. The in vitro biomedical and diagnostic applications of QDs include such techniques as the multicolor fluorescent labeling of cell surface molecules and cellular proteins in microscopy and other applications, detection of pathogens and toxins, DNA and RNA technologies, and fluorescence resonance energy transfer. QDs are also being explored for use in whole-body in vivo imaging of normal and tumor tissues. QDs may also find use in therapeutic applications such as targeted drug delivery, photodynamic therapy, and drug discovery [24]. 


\section{Cadmium-containing quantum dots}

Different results by various research groups indicate that cadmium (in group III-V) is extremely toxic if allowed to leach into the environment and this material also has DNAdamaging properties [25]. Other studies have shown that using cadmium in the cellular environment may lead to the formation of reactive oxygen species, resulting in cell death [26, 27]. The stability of groups III-V is known to be due to the presence of covalent rather than ionic bonding. The most optically suitable emitting 'core' materials have been cadmium-based materials. Cadmium selenide, Cadmium sulfide or Cadmium telluride particles provided bright emission across the visible and near infrared regions of the electromagnetic spectrum [28]. Questions have arisen regarding the suitability of cadmium-containing materials as biological labels. Other problematic factors include the suitability of the capping agents, the retention of particles over a certain size, biological magnification and, importantly, the breakdown and decomposition products of these inorganic materials. QDs are notoriously labile and the identity and ultimate destination of the inorganic decomposition products remains unclear. Despite this, cadmium-containing quantum dots provide a genuine advance in medical imaging and the numerous problems involving these particles are almost immediately dispelled if one wishes to image and explore fixed cells [29, 30].

Cadmium, which is the main component in the majority of quantum dots, is known to be acutely and chronically toxic to cells and organisms. In cells, it is taken into calcium membrane channels, where it accumulates [31]. Cadmium inhibits the synthesis of DNA, RNA and proteins, as well as breaking up DNA strands and mutating chromosomes [32]. On a cellular level, cadmium induces oxidative stress by depletion of endogenous antioxidants such as glutathione [33], as well as mitochondrial damage [34]. Cadmium nanoparticles exposure can lead to disturbances in cellular homeostatic mechanisms, resulting either in adaptive cellular responses or cell death. Cell death can occur either through an abrupt process named necrosis or a tightly regulated or programmed process (apoptosis and autophagy) [35]. Its toxicity is mainly associated with liver and kidney injury, osteoporosis and neurological dysfunctions at the level of living organisms. The toxic ions are commonly thought to be released from quantum dots when the surface of the nanoparticle is oxidized and early reports on the inclusion of simple quantum dots in bacteria support this [36]

Protecting the core can, to some degree, control toxicity related to cadmium leakage. However, the change in the physicochemical and structural properties of engineered quantum dots could be responsible for a number of material interactions that could also have toxicological effects $[37,38]$. However, encapsulation is not simple and it has been reported that quantum dots have displayed toxicity even with well-protected cores. Recently, polymers that can act as coordination sites for cadmium ion aggregation have protected semiconductor nanoparticles. CdS nanoparticles protected with starch and, in particular, amylose, form a wide range of inclusion complexes for numerous guest molecules [39]. Soluble starch added during the synthesis has been used as a capping agent in the synthesis of CdS and CdSe nanoparticles, resulting in well-controlled and uniform particle sizes of cadmium-rich nanoparticles [40]. Early studies attempted to quantitatively determine values for the onset of cytotoxicity in CdSe 
and CdSe/ZnS quantum dots, either coated with mercaptopropionic acid (MPA), embedded in a silica shell or embedded in an amphiphilic polymer shell [41]. They found that the majority of the nanoparticles were ingested into the cells and were stored in vesicles around the nucleus, irrespective of the surface coating. We have previously synthesized CdS nanoparticles coated with maltodextrin polymer, and our results revealed that CdS-MD nanoparticles produced distinct dose-dependent effects (Figure 2) [42]. It is clear from this and other studies that the surface coating is related to the toxicity experienced by cells, which affects the level of toxic material released from the nanoparticles. Other studies have shown that different cell types have varying thresholds for quantum dot-induced toxicity.

(A)

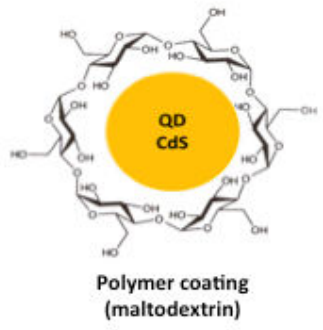

(C)

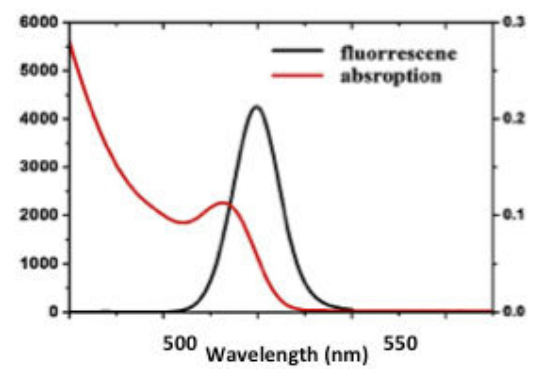

(B)

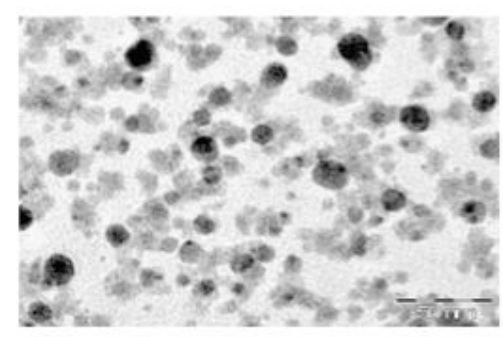

(D)

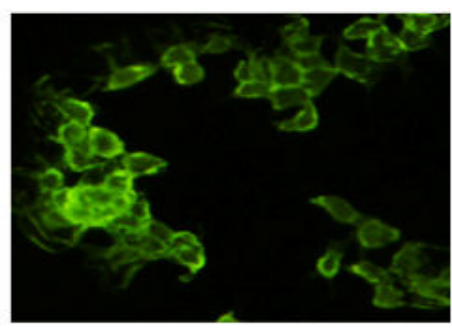

Figure 2. CdS/maltodextrin quantum dots. (a) Schematic structure of CdS/maltodextrin quantum dots; (b) Characterization of different sized CdS/MD quantum dots using TEM; (c) Spectra of CdS/MD quantum dots, the maximum luminescence of which is a wavelength of $520 \mathrm{~nm}$ (CdS/MD520); (d) HepG2 cells observed under fluorescent microscopy at (x40) magnification.

\section{Biocompatibility and functionalization of cadmium-containing quantum dots}

Biocompatibility is a word that is used extensively in biomaterials science. The incorporation of QDs into biological systems often requires strategies for the manipulation of the ligands bound to the surface of the QDs surface in order to make them water-soluble and biocompat- 
ible, compatible with living tissue or a living system by not being toxic, injurious, or physiologically reactive [43]. QDs must be rendered water-soluble through the modification of their surface in preparation for biological applications. An ideal water-soluble ligand should meet the following requirements: (1) provide QDs with stability and solubility in biological buffers; (2) maintain a high resistance to photobleaching and other photophysical properties in aqueous media; (3) have functional groups which are able to conjugate to biomolecules; (4) minimize overall hydrodynamic size. The stability of QDs in water can be obtained through either a complete ligand exchange procedure, or through steric stabilization where the native hydrophobic surface is coated with amphiphilic molecules and/or polymers [44, 45].

QDs have been adapted to the desired application by conjugation to a recognition moiety, e.g., antibodies, peptides, oligonucleotides or aptamers, or by coating with streptavidin. Several functionalizations have been adapted to the shell layer coating the core, making the core/shell QDs most adaptable for biological applications [46]. In order to suitably functionalize the QDs, there are several methods that have been successfully used for conjugation of QDs to the desired biomolecules. These include electrostatic attraction, covalent linkage, adsorption, and mercapto (-SH) exchange [47]. The choice depends on the features of the biomolecule of interest; for example, thiol-containing biomolecules can be conjugated to QDs via mercapto exchange. In contrast, simple small molecules such as oligonucleotides and various serum albumins were found to readily adsorb non-specifically to the surface of water-soluble QDs. The factors affecting the adsorption are $\mathrm{pH}$, ionic strength, temperature, and surface charge of the molecules [48]. There are three primary ways to target a biocompatible and functional quantum dot: with antibodies, with peptides, or with small molecules. The simplest labeling strategy uses antibodies; the most complicated is that of small molecules, as this approach usually requires more synthetic chemistry. Each approach has its advantages and disadvantages, and no approach is a universal solution.

Chemical conjugation of antibodies to semiconductor QDs is attractive because the proteins of interest can be visualized. For conjugation of QDs to antibodies, the orientation of the antibody on the QD is important given its functionality as a targeting moiety. The conjugation strategy contributes to the control of antibody orientation. For example, the use of biotinylated antibodies and streptavidin-coated QDs provides no control over the orientation of the antibody on the surface of the QD owing to the presence of multiple biotinylation sites on the antibody. Antibody-quantum dot conjugates have been used in a myriad of applications [49, 50]. An immunoassay for the detection of hepatitis B surface antigen [51] conjugated $\mathrm{CdTe} / \mathrm{CdS}$ QDs to anti-hepatitis B surface antigen antibodies using protein G as a linking bridge, instead of covalently linking the QDs to the antibodies. Other studies developed a microplate immunoassay for detection of the cardiovascular marker C-reactive protein in 104 serum samples, with a limit of quantification of $0.19 \mu \mathrm{g} / \mathrm{l}$ within $1.5 \mathrm{~h}$ [52]. A multiplex immunoassay for the simultaneous detection of staphylococcal enterotoxin B and chicken IgY (IgG) in the same well of a 96-well microtiter plate was also undertaken [53]. A multiplex fluoroimmunoassay for the detection of lung cancer markers - neuron specific enolase (NSE) and carcinoembryonic antigen (CEA) in human serum - was recently developed [54]. A wide selection of antibody-quantum dot conjugates is also commercially available. Disadvantages 
to this approach include the availability of antibodies, their selectivity and affinity, and the increased hydrodynamic radius of the quantum dot conjugate. Nonetheless, antibody-QD conjugates are often the method of choice and make up much of the QDs in biology literature.

Peptides can also be conjugated to QDs in a direct approach by linking to thiol-rich domains. A direct binding approach was used to bioactivate and solubilize QDs with phytochelatinrelated peptides [55]. Peptide-functionalized quantum dots have been successfully used for targeting cellular proteins such as growth factor receptors, $G$ protein-coupled receptors, integrins, and ion channels [56, 57]. In particular, $30-50$ arginine-glycine-aspartatic acid (RGD) peptides have been conjugated to NIR quantum dots to specifically target $\alpha \mathrm{v} \beta 3$ integrins in mouse tumor neovasculature in vivo [58], while other studies have relied on high-affinity peptide neurotoxin quantum dot nanoconjugates to image endogenous proteins in living cells and ex vivo tissue [59]. Overall, peptide-quantum dot nanoconjugates offer distinct advantages over antibody-mediated targeting, and their potential as biological probes is being actively explored. On the other hand, a single QD can be conjugated to multiple protein molecules, which can be similar or different depending on the intended application. Approximately 15-20 maltose binding proteins, a $44-\mathrm{kD}$ a protein measuring $3 \times 4 \times 6.5 \mathrm{~nm}$, can be attached to a single 6-nm QD [60]. Because of their brightness and photostability, water-stabilized QDs have been used to track many receptor-mediated endocytic trafficking events in live cells using fluorescence microscopy [61]. For example, QDs conjugated to EGF have been used to track the dimerization of the EGF receptor (EGFR) and its ability to elicit downstream signal transduction events [62]. Biotinylated $\alpha$-bungarotoxin was bound to streptavidin-conjugated QDs to characterize the assembly dynamics of acetylcholine receptor clusters in postsynaptic membranes [63]. Recently, high-resolution imaging methods in the nanometer range have been developed to image the membrane transport and dynamics of tumor cell proteins during metastasis in living mice using antibody-conjugated QDs [64]. This technology can also be applied to detecting cancer cells in sentinel lymph nodes in whole animals using QDs conjugated to tumor-specific molecules [65]. One can envision several ligand-conjugated quantum dots, with each ligand conjugated to a different size (color) quantum dot, allowing a multiplexed fluorescent assay for drug discovery.

Different schemes have been developed to conjugate ssDNA and dsDNA to the surface of QDs. DNA-QD conjugates retain the selectivity of DNA and the photophysical properties of QDs, allowing detection of single or multiple DNA targets. DNA-QD conjugates require solubility in water, stability under physiological conditions and minimal nonspecific DNA binding to the QD surface. The thiol-modified oligonucleotide can be conjugated to QDs in a direct ligand exchange approach (native cap exchange) where the oligonucleotide displaces the surfacebound mercaptopropionic acid and yields aqueous stable and strongly fluorescent oligonucleotide bound QDs [66]. Applications of QDs include in vitro diagnostics, imaging and therapeutics. QDs are used as labels in immunoassays, immunohistochemical staining, cellular imaging and multiplex diagnostics. 


\section{Cadmium-containing quantum dots as a platform for nanoparticle drug delivery vehicle design}

Recently, there has been an explosion in the development of nanoparticle-based drug delivery vehicles composed of lipids, polymers, carbon materials, and even hybrid combinations of those materials tailored not only for the dramatic improvement of the pharmacological properties of existing drugs, but also for enabling the delivery of new classes of potent anticancer drugs for gene therapy and immunotherapy $[67,68]$. With QDs, a combination of unique physical, chemical, and optical properties facilitates in-depth study of nanocarrier interactions with biological systems through real-time monitoring of QDs biodistribution, intracellular uptake, drug release, and long-term nanocarrier fate. At the same time, compact size and compatibility with a variety of surface modification strategies enables substitution of virtually any QD core with a QD within single-nanoparticle drug delivery vehicles, or incorporation of QD tags within larger multicomponent vehicles. The combination of superior brightness and resistance to photo-degradation represents another set of QD properties that highly useful for long-term nanocarrier tracking.

The great interest in engineering NP-based drug delivery vehicles is driven by the powerful capability of nanocarriers to completely redefine the pharmacokinetic properties of virtually any drug, ranging from small-molecule therapeutics to large proteins and DNA plasmids. Encapsulation of the drug within the nanoparticles keeps it shielded from the biological environment until the moment of carrier degradation and drug release, thus minimizing nonspecific and potentially adverse interactions en route to the target [69].

A few reports have appeared recently regarding this ambitious goal. It has previously conjugated captopril, an antihypertensive drug, to the QD surface and studied its pharmacodynamics and pharmacokinetics in stroke-prone spontaneously hypertensive rats [70]. The results show that the administered QD-captopril conjugates are capable of decreasing rat blood pressure to the same extent as the captopril alone in the first $30 \mathrm{~min}$, but the therapeutic effect of QD-captopril disappears after $60 \mathrm{~min}$. It is unclear whether the therapeutic effect results from the QD-captopril conjugates or captopril molecules detached from the QD surface. Another piece of interesting work was previously reported, wherein a targeting functionality was added to QDs by linking them with RNA aptamers (A10) that specifically bind to prostate specific membrane antigen (PSMA) [71]. Doxorubicin, a DNA-interacting drug widely used in chemotherapy, was immobilized onto QDs by intercalation within the A10 RNA aptamer [72]. Another study reported the ability of nanoconjugates of CdSe/CdS/ZnS and doxorubicin (Dox) to target alveolar macrophages, cells that play a critical role in the pathogenesis of inflammatory lung injuries. The results demonstrated that nanoparticle platforms can provide targeted macrophage-selective therapy for the treatment of pulmonary disease [73]. This was previously reported regarding siRNA delivery using QDs as delivery vehicles [74].

QDs already play an important role in fundamental biology and in vitro disease diagnostics and prognostics. Their unique structural and surface properties, such as their tunable and uniform size, flexible drug-linking and doping mechanisms, large surface-to-volume ratio and wide spectrum of surface reactive groups have enabled a new avenue of research: targeted 
and traceable drug delivery. However, high-quality QDs are mainly made with heavy metals, like cadmium, whose long-term toxicity is currently largely unknown. Despite this limitation, QDs have been applied to cells and small animals as drug carriers, serving as an outstanding discovery tool for drug screening and validation, and as prototype materials for drug carrier engineering [75]. One primary challenge of drug delivery is maintaining a useful concentration of the drug in the targeted tissue while preventing toxicity.

\section{Pharmacokinetics of cadmium-containing quantum dots}

Nanoparticle-based drug delivery is on its way to overcoming the fundamental limitations of simple free drug formulations, providing means to change their pharmacological properties and also understand their biological fate in great detail. Among many contrast agents for studying nanoparticle-based drug delivery vehicles, QDs are particularly suitable. Their unique amalgamation of useful features, such as small size, versatile surface chemistry, and exquisite optical properties make them an ideal platform for the comprehensive characterization of nanoparticle-based drug delivery vehicle behavior across single-cell to whole organism levels. In this new field, QDs have already made substantial contributions, enabling dynamic monitoring of nanocarrier cell uptake, intracellular distribution, circulation half-times, and biodistribution. Early on, the design of QDs drug delivery vehicles was governed by the intrinsically poor pharmacokinetic (PK) properties of conventional drugs. Low drug solubility, rapid metabolism and clearance and, most importantly, a lack of selectivity, regularly lead to therapeutic failure by causing severe systemic toxicity in healthy tissues, thus prohibiting the dose escalation necessary to eliminate tumor cells. Incorporating these drugs into nanocarriers offers an exciting opportunity to redefine the PK properties, improving therapeutic efficacy and reducing side effects.

When we utilize a nanopharmaceutical, it is important to realize that, in contrast to delivering a drug that is an organic molecule, we are delivering something of a discrete entity in a nanoparticle-comprised of atomic scale parts. Due to the quantum effects and electronic interactions that predominate at the nanoscale, we need to alter the way in which we think about pharmacological parameters in order to adapt to nanoscience. Nanopharmacology is further complicated by the need to establish the behavior of nanoparticles such as QDs within the traditional pharmacological parameters of absorption, distribution, metabolism and excretion (ADME). Nanoconstructs, in many cases, have limited metabolism and excretion and persist in biological systems; this becomes particularly important when toxic atoms such as cadmium are involved. The pharmacological parameters of the behavior of cadmiumcontaining quantum dots in biological systems is currently still under investigation. Dosing parameters, absorption, distribution, metabolism and excretion require considerable further study, since we have little information on these parameters at this point.

The first factor we need to establish before we study the pharmacokinetics parameter is the dose. Adequate estimates of QDs exposure during treatments such as cancer therapy must be in place so that both pharmacological and toxicological studies can be conducted within a 
physiologically relevant dose range. Importantly, how does cadmium content relate to dose? To date, these parameters have not been rigorously addressed. Dose metrics of QDs have been reported in terms of $\mathrm{mg} / \mathrm{kg}$ (or $\mathrm{mg} / \mathrm{ml}$ for in vitro studies) or on a molar basis, and this will no doubt need refinement. Given that a QD, or any other nanoparticle, is an engineered entity or "mini-reactor", dose via mass or molar number may be an inappropriate descriptor. The length and extent of QDs tissue retention is an important parameter for dosing considerations, since repeated doses may induce systemic accumulation, contributing to potential toxicity. Furthermore, persistence of QDs in tissues demands long-term studies to accurately assess risk. Therefore, the dose is another parameter that requires consideration.

The second factor to establish is the route of administration. This, along with the risks for exposure and possible toxicity should be addressed cautiously to ensure experimental and clinical safety. Moreover, an understanding of possible interactions of QDs within human tissues may shed light on the prevention of health risks in the laboratory and daily exposure to QDs. To date, research has established that various nanoparticles can enter an organism through skin, inhalation, oral delivery, and parenteral administration. Intravenous injection is a major route for drug administration. It has been reported that intravenously injected QDs may accumulate in unintended tissues, which implies that the potential toxicity might result from a failure to clear them from the body [76]. The possibility of tissue uptake of QDs via ingestion following exposure has also been proposed in animal and cell culture models. Skin is another important portal of entry for nanoparticles as potential route of systemic drug administration.

The abilities of nanoagents to penetrate the skin barrier are debatable. Some studies indicate that NP penetrate skin barrier under skin lesions, UV sunburn or ultrasound [77]. The potential beneficial and/or side effects of intradermally accumulated NP primarily depend on their localization in the tissues. It is also important to elucidate further migration pathways of particles, as this would determine their pharmacokinetic properties and systemic distribution in the organism. Topically applied QDs were reported to accumulate in the dermis and muscles [78]; however, a more detailed localization of particles has not been described. Other studies reported that the majority of the intradermally injected QDs remained at the injection site and a minority of QDs migrated into lymph nodes, highlighting QDs advantages for lym-phatic imaging $[79,80]$. However, high retention of QDs at the injection site raises concerns about long-term physiological effects. There is a lack of in-depth analyses of QDs localization and migration pathways in the dermis. It was recently reported that the subcutaneous injection of CdSe/ZnS coated with mPEG-5000 polymer into the CDF1 of mice showed that basement membrane and dense connective tissue fibers limited the diffusion of QDs in the dermis [81]. Negligible QDs penetration into the epidermis, hair follicles, sebaceous and sweat glands, nerves and blood vessels was also observed. However, low permeation of QDs through the tissues could result in slow clearance and raises the risks of potential immune, inflammatory and cytotoxic responses.

The cornea is another common route of drug administration and also an important route of nanoparticle exposure in occupational scenarios and daily life. However, the possibility of QDs penetration into the cornea has not been discussed before. It has been previously demonstrated 
that specific QDs influence corneal stromal cell viability up to a significant magnitude of $50 \%$ in a relatively low concentration (5-20 $\mathrm{nM}$ ) and under a short exposure period (24-48 h) [82]. QDs can also be retained in the cornea up to 26 days in an in vivo mouse model. Therefore, since corneal stromal cells are crucial for the maintenance of the health and transparency of the cornea, potential QDs cytotoxicity due to bioaccumulation is a major concern given the potential threat to corneal health.

Absorption via tissues and biological fluids is generally the first hurdle to be met and this is, of course, dependent on route of delivery. Currently, the most important route of delivery for QDs appears to be systemic distribution through parenteral delivery [83]. Nanoparticles are considered to absorb more effectively into the respiratory, skin, and gastrointestinal systems than micron-sized particles because of their unique physicochemical properties, such as their size and surface modifications [84]. For example, instillation of $5 \mathrm{~nm}$ QDs shows faster translocation to other organs than in the case of $27 \mathrm{~nm}$ QDs [85]. In addition, a recent study showed that nanoparticles were only translocated into the circulation system when administered into the lung; their absorption rate varied, depending on their surface properties [86]. When different sizes of polystyrene QDs were administered orally to rats, the absorption of 50-100 nm polystyrene QDs was about 250-fold higher than the absorption of larger microparticles $(500 \mathrm{~nm}, 1$, and $10 \mu \mathrm{m}$ ) [87]. Oral administration of different sizes of colloidal gold particles to mice showed size-dependent absorption [88]. Regarding surface modification, positively charged particles show better absorption than neutral or negatively charged particles [89]. However, in a recent study using gold nanoparticles, negatively charged particles showed higher absorption rates than positively charged particles [90]. Therefore, no general rule can be made about absorption from these results and further studies on the impact of surface modification on gastrointestinal absorption are required. Studying the kinetics of nanoparticles is an important issue in nanotechnology.

Regarding distribution, one of the first elements that parenteral delivered QD will encounter is the environment of the blood. Here, we have little to no information about blood/QD interactions. Plasma half-life is no doubt related to surface coating and addition of biological targeting ligands, if any. For example, PEG coating was reported to increase plasma half-life [91]. In the case of oxide nanoparticles, many are coated with endogenous plasma proteins immediately upon entry into the circulatory system and this appears to enhance tissue delivery. However, the interactions between QDs and plasma proteins are unknown. Immune responses may also be triggered at this level, as reviewed by [92], but the precise interactions of QDs at this level have not been examined. Recently, some studies have investigated the in vivo biodistribution of QDs [93-95]. All of the reports in the literature unanimously conclude that QDs show a preference for deposition in organs and tissues and that they do not remain circulating in the bloodstream [96]. Real-time imaging of live animals treated with the hyaluronic acid (HA)-conjugated QDs showed that the luminescence of NIR QDs could be detected for up to 2 months [97]. Others reported that QDs coated using an amphiphilic poly(acrylic acid) polymer remain fluorescent after at least four months in vivo [98].

Organ-selective biodistribution and elimination routes of synthesized QDs coated with 3mercaptopropionic acid (QD MPA) and commercially available Qtracker 705 nontargeted 
quantum dots with poly(ethylene glycol) coating (QD PEG) were recently compared after intravenous injection to mice. QDs were deposited mainly in liver, spleen, kidney and lymph nodes [99]. Another study observed that, in the murine model, quantum dots (CdSe 100 pmol/ $\mathrm{kg}$ ) administered by intravenous injection mainly accumulated in the red pulps of the spleen, portal areas of the liver, and adrenal glands of the kidney within $1 \mathrm{~h}$. It is believed that quantum dots do not degrade, as evidenced by the intensity of the fluorescence in the fluorescence spectrum image and comparable intensity profile of Cd [100]. One consistent theme in the existing literature is that QDs are eventually taken up by the reticuloendothelial system, including the liver, spleen, and lymphatic system [101]. On the other hand, it has been found that aqQDs are initially accumulated in liver after short-time (0.5- $4 \mathrm{~h})$ post-injection, and then are increasingly absorbed by kidney during long-time (15 - 80 days) blood circulation. Moreover, size-dependent biodistribution is obviously observed: aqQDs with larger sizes are more quickly accumulated in the spleen [102]. We have recently found that after i.p. injection, the CdS/Maltodextrin quantum dots mainly accumulated in the liver, kidney, spleen, thymus, intestine, lung and brain (Figure 3). The pharmacokinetics studies showed the presence of CdS/ Maltodextrin in kidney 30 min after administration; at $18 \mathrm{~h}$, the presence of quantum dots in kidney was more abundant. However, the amount of CdS/Maltodextrin quantum dots in liver was lower than in kidney, and the maximal presence was at $3 \mathrm{~h}$. Our results suggest that the transition of CdS/Maltodextrin quantum dots via the liver is very fast, and the main route of elimination is renal (Figure 4).
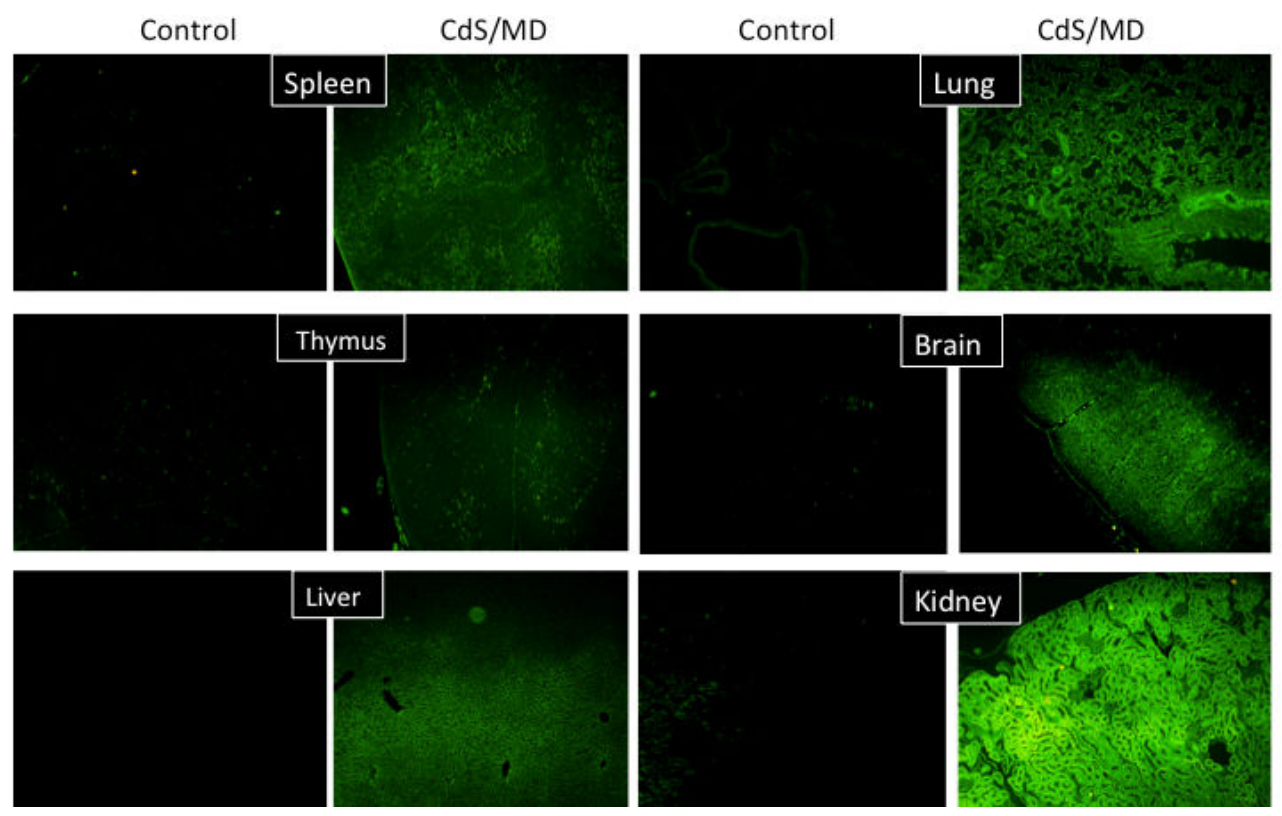

Figure 3. Biodistribution of CdS/Maltodextrin in Wistar rats. Tissue distribution of CdS/maltodextrin quantum dots after i.p. administration of $10 \mu \mathrm{g}$ during 8 days. Quantum dots were observed in all analyzed tissues, including brain. The maximal observed presence of quantum dots was in lung and kidney. 

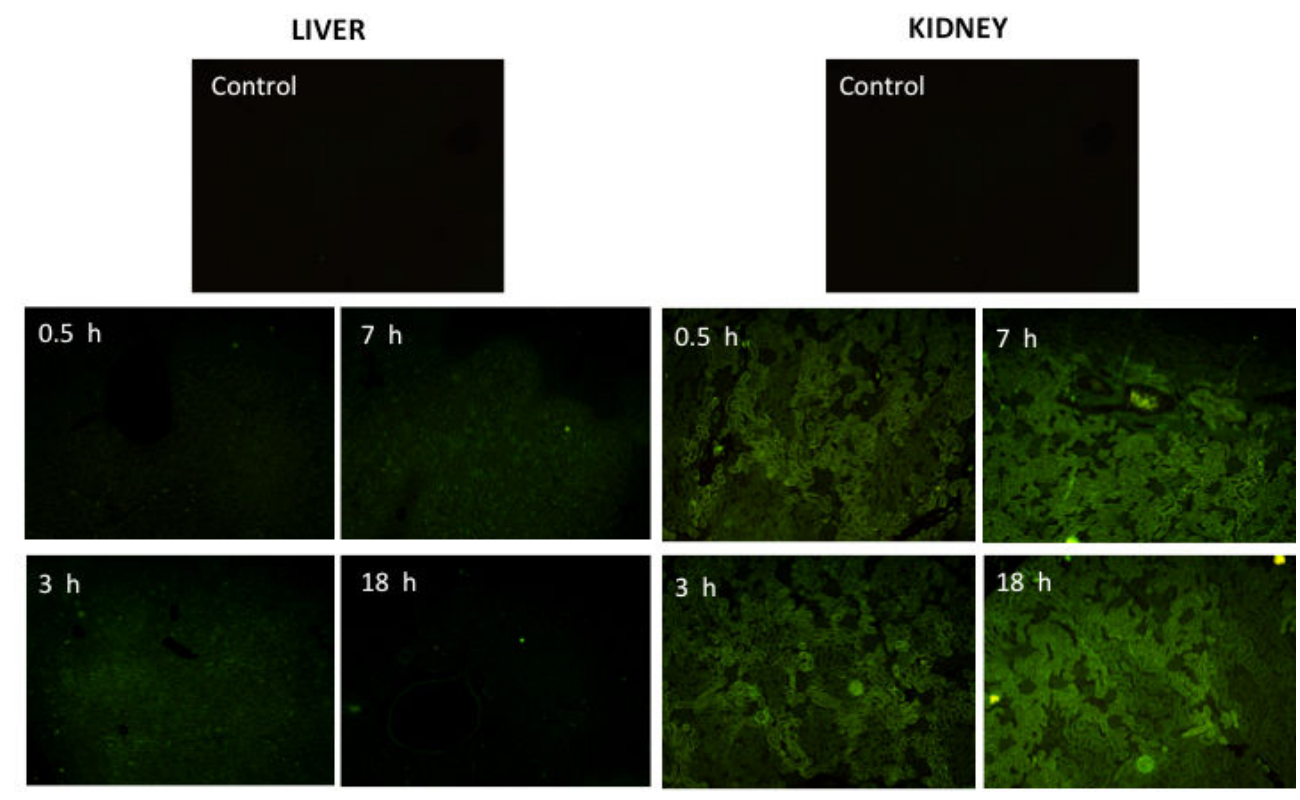

Figure 4. Biokinetics of excretion of CdS/maltodextrin quantum dots after a single i.p. administration of $10 \mu \mathrm{g}$ in kidney and liver.

The blood-brain barrier (BBB), is a critical interface and acts as a physical and metabolic barrier between the CNS and the peripheral circulation that serves to regulate and protect the microenvironment of the brain. The primary function of the normal BBB is to establish and maintain homeostasis in the CNS [103]. Under normal physiological conditions, BBB prevents transport of bacteria, large molecules, and most small molecules into the brain. To be BBB permeable, molecules need to be lipid soluble and less than $400 \mathrm{Da}$ in size. There are more than 7000 drugs in the comprehensive medicinal chemistry database, and only $5 \%$ of these drugs can be used to treat the CNS diseases. In a related study, $12 \%$ of all drugs are shown to be active in the CNS, but only $1 \%$ of all drugs are active in the brain for diseases other than affective disorders [104]. The importance of developing new approaches to brain drug development is illustrated by considering the limitations of the existing brain drug delivery strategies. Therefore, there is great interest in nanomedicine to develop optimized traceable drug-loaded nanoparticle formulations that can be safely used to facilitate drugs across the BBB for treating brain diseases and, at the same time, visualizing the distribution profile of the nanoparticles in the brain. The use of QDs bioconjugates as efficient targeted probes for transmigration across the BBB has been previously demonstrated [105]. Since the transferrin receptor protein is highly localized on the endothelial surface of the brain, transferrin (Tf) was selected to trigger receptor-mediated transport across the BBB. It was discovered that the migration rate of Tfconjugated QDs crossing the in vitro BBB is both concentration-and time-dependent [106]. It was recently demonstrated that the QDs-Tf-Saquinavir nanoformulation increases the drug solubility, enhancing systemic bioavailability, while the excellent optical properties of QDs 
also visualize the distribution and accumulation of nanoplexes in brain [107]. Such primary results offer a basis for the development of novel QDs with targeting molecules and drugs, which could enhance drug delivery efficacy across the BBB and facilitate the uptake of the QDdrugs in the brain. Despite the encouraging results on the use of QDs for drug delivery across the $\mathrm{BBB}$, there is still serious concern regarding QDs toxicity in vivo, which mainly originates from the intrinsic, potentially toxic nature of the semiconductor materials themselves.

On the other hand, the placental barrier protects the embryo from various chemical agents and other foreign substances in the body. However, the passage of xenobiotic molecules through the placental barrier is not completely prevented, and drugs may affect fetal cell proliferation, embryonic growth, and organ formation [108]. Knowledge regarding embryotoxicity is of great importance because it is a necessary part of the toxicological profile that must be established for any new biologically active substance relevant to human safety. There are many studies in this field [109-111], but the detailed effects of NPs still pose many questions. A decrease in embryonic weight after QDs injection on the sixth day of embryogenesis (CdSe/ZnS QDs, 9.6\%; CdT QDs, 6.2\%) has been reported, and no embryotoxic or teratogenic effects were observed at any stage of embryogenesis [112]. Others have shown that NPs (nSP and $\mathrm{TiO} 2 \mathrm{~s} 70 \mathrm{~nm}$ and $35 \mathrm{~nm}$ in diameter, respectively) can cross the placental barrier in pregnant mice and cause neurotoxicity in their offspring [113]. They showed that the NPs were found in the placenta, fetal liver, and fetal brain. Other authors argue that some NPs (CdSe and $\mathrm{CdTe} / \mathrm{CdS}$ ) in different sizes, at different dosages, and with different outer capping materials can increase the rate of early-stage blastocyst death in mice and can be potentially transferred across the placenta to the fetus $[109,114]$. These studies show that NPs can enter the embryo through the placenta, which is a natural barrier for a large variety of organic substances with diverse molecular structures. The NPs, which appear in the maternal body during pregnancy, can cross the placental barrier and may even cause developmental deformities. Recently, we demonstrated that CdS-MD nanoparticles were embryotoxics in a chicken embryo model (Figure 5) [42]. The nature of the observed abnormalities suggests that these effects could be directly associated with concentration. Therefore, according to the observed effects, the prolonged accumulation of quantum dots in the maternal organism may increase the risk of adverse effects on embryo development.

The liver is know to have a high capacity to metabolize and degenerate a multitude of xenobiotics. The binding of proteins plays a key role in delivering xenobiotics from plasma into the liver. In addition, the reticuloendothelial system (RES) can phagocytose particles larger than $100 \mathrm{~nm}$ and then transport the particles into the liver in vivo. Metabolism of QDs is yet another understudied aspect of cadmium QDs. The QD cores do not appear to be subject to extensive enzymatic metabolism, but shells and coatings are. The extent of metabolism of the shell and coating becomes critical for toxicity, since they shield the more toxic CdSe or CdTe cores from the intracellular environment. Rather than metabolism per se, degradation of the shell and coatings within the biological environment appear to be more important. QD shells and coatings appear to degrade under photolytic and oxidative conditions, yet we know little about the degradation products or their biological effects, which may regulate release of toxic cadmium cores. The behavior of nanoparticles in vivo depend on properties such as the 

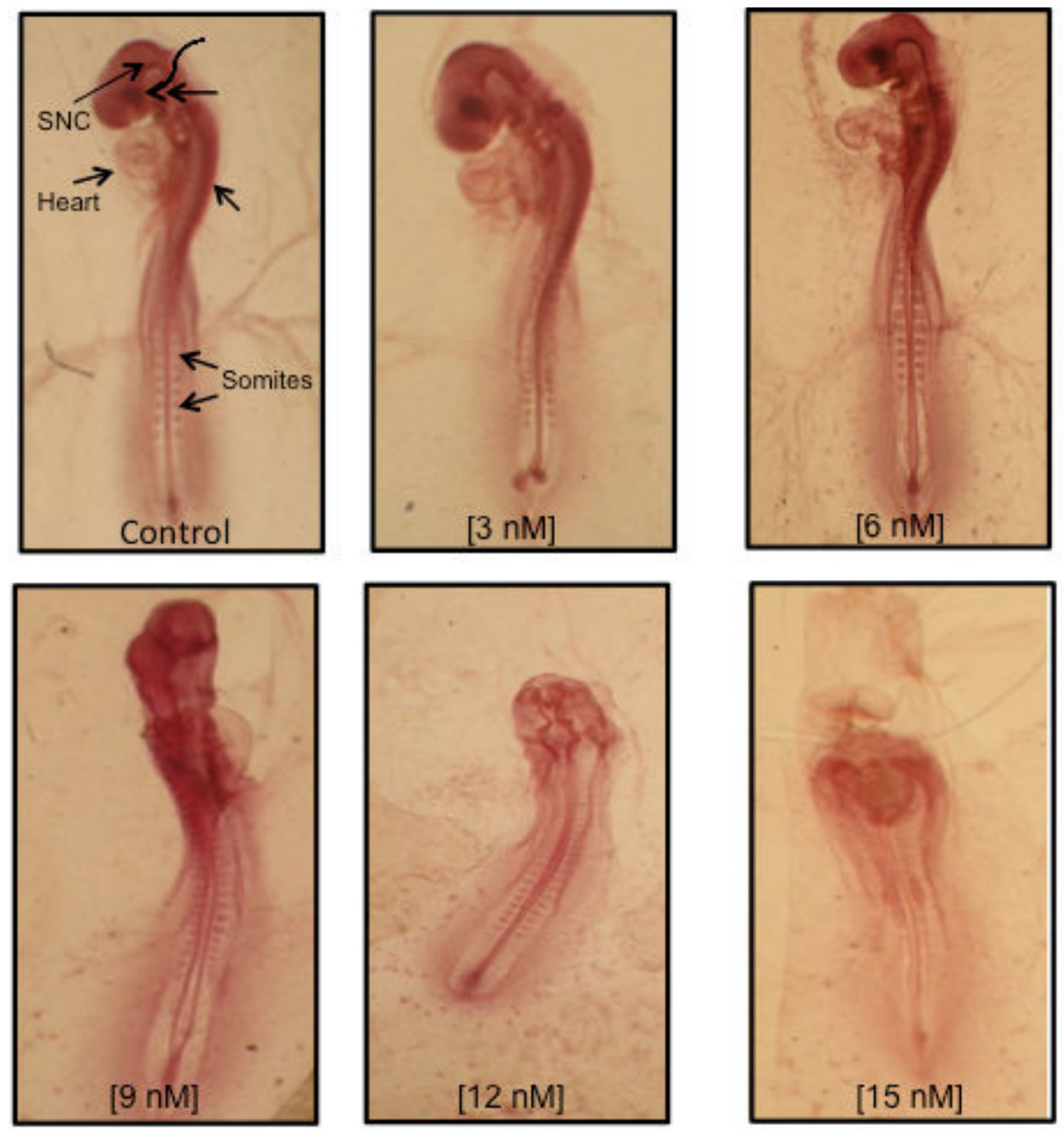

Figure 5. Photographs of $72 \mathrm{~h}$-old chick embryos treated with CdS/Maltodextrin. Observed alterations were dose dependent.

nanosize (surface area and size distribution), chemical composition (purity, crystallinity, electronic property, etc.), surface structure (surface reactivity, surface groups, inorganic or organic coatings, etc.), solubility, shape, and aggregation [115]. It has been suggested that the metabolic paths of QD nanoparticles are closely correlated to their aggregation states, and three metabolic paths were disclosed after intravenous injection: 1) the QDs that maintained their original nanosize without binding in vivo were rapidly excreted via the kidney; 2) some QDs binding to proteins were translocated to the liver and were excreted with feces; 3 ) a small 
fraction of the QDs aggregated to larger particles and were retained in liver tissue for a long time [116].

Several studies suggest that the kidneys can remove QDs that are less than $5 \mathrm{~nm}$. It has been observed that, after i.v. administration of CdSe/ZnS-QDs, only $10 \%$ and $40 \%$ of the injected dose was found in the kidney and liver respectively, suggesting that only a fraction of the total QDs dose passed through this route [117]. Another study quantitatively detected the excretion of QDs in mice feces and urine after i.v. injection of CDSe QDs. The speed of excretion was quicker via feces, and the peak $(0.214 \mathrm{ng}$ of $\mathrm{Cd})$ occurred $6-12 \mathrm{~h}$ postexposure. The excretion from urine was relatively delayed, and the peak ( $0.174 \mathrm{ng}$ of $\mathrm{Cd})$ was $24-36 \mathrm{~h}$ post-exposure [118]. The elimination of silica-coated CdSe QDs ( $\sim 5.5 \mathrm{~nm})$ from the body via feces and urine occurred in its totality after 5 days. Yet many reports propose that a portion of the administered QD dose may not be excreted and remains in the tissues. The extent of excretion and the extent of persistence in tissues take on added importance when one considers the potential delivery of QD as a cancer-targeting drug. More comprehensive studies of potential excretion will therefore be critical to QD development as a nanopharmaceutical.

Numerous studies have addressed the cellular level, but these are often difficult to compare due to varied dosing parameters and lack of physicochemical particle characterization. In general, it appears that most QDs examined found ready uptake at the cellular level, primarily via endocytic mechanisms, which depends upon the surface ligands coated over the QD surface $[119,23]$. It has been reported that CdSe QDs and CdTe QDs that enter the cell, are visible at the cell surface and in the cytoplasm after a short time. QDs are likely to bind to the cell surface due to their interaction with cell surface glycoproteins and glycolipids [66]. Employing red-and green-emitting cationic QDs, it was found that the CdTe QD distribution was in part dependent on nanoparticle size. In the murine microglial N9 cell line, red cationic QDs (5 $\mathrm{nm}$ ) were distributed throughout the cytoplasm. In contrast, green and also positively charged QDs (2 nm) were often found in the nucleus of N9 cells upon $1 \mathrm{~h}$ of QD exposure [120]. It has been shown that green QDs coated with tri-metoxysilylprolyl urea and acetate groups bind with high affinity in the cell nucleus of mouse 3T3 fibroblasts [121]. In human mammary epithelial tumor cells (MDA-MB-231) green-emitting CdSe/ZnS/SiO2 QDs were packaged in large vesicles found in the perinuclear region [23]. Confocal images have showed that MPAcoated QDs were distributed inside the cytoplasmic region of cells. In contrast, GA/TOPOcoated QDs were not found inside cells. These results indicate that cellular uptake of QDs depends upon the hydrodynamic size of the QDs as well as surface coating material [122]. These results strongly suggest that surface coatings can improve cytocompatibility and, consequently, decrease toxicity. Previous studies have shown that long-term exposure of surface coated QDs to their bioenvironment can destabilize the binding strength of the surface molecules, which in turn can yield unprotected QDs inside or outside the cells [123]. Therefore, the stability and binding strength of surface molecules over the QD surface define the cytocompatibility of the QDs and hence their cytotoxicity. Thus, according to previous studies: (1) the surface coating strategy could improve the cytocompatibility of QDs, (2) surface molecules could determine the intracellular uptake and consequent cytotoxicity of QDs, and (3) intracellular uptake of QDs could depend on their hydrodynamic size. 


\section{Strategies for safe drug delivery using cadmium-containing quantum dots}

Discussion regarding the toxicity of cadmium-containing QDs can be somewhat confusing because of the diversity QDs being synthesized. Besides and as we have mentioned before, we have to consider that not all QDs are alike. Each individual type of QD possesses its own unique physicochemical properties, which in turn determine its potential toxicity or lack thereof [124]. In general, there are discrepancies in the current literature regarding the toxicity of QDs and these can be attributed to several factors: the lack of toxicology-based studies, the variety of QD dosage/exposure concentrations reported in the literature, and the widely varying physicochemical properties of individual QDs.

Up to date, toxicity studies have been conducted on a variety of both human and non-human cells and cell lines; research has been focused on in vitro assays of cytotoxicity [125-131]. In vitro studies are very important and can serve as background data to inform the design of in vivo studies but, on their own, they provide an insufficient basis for a complete risk assessment. Administration of QDs in animal models has revealed that QDs induce: (1) accumulation of QDs in specific organs [23, 132, 133], (2) excretion in urine, bilis and feces [134], (3) toxicity in selective organs [135], (4) embryotoxicity [109, 111], and (5) oxidative damage [136-138]. Importantly, and a potential source of confusion in assessing QD toxicity, the latter depends on multiple factors derived from both individual QD physicochemical properties and environmental conditions: QD size, charge, concentration, outer coating bioactivity (capping material, functional groups), and oxidative, photolytic, and mechanical stability have each been shown to be determining toxicity factors. Therefore, all these aspects should be extended to examine alternate QD formulations, compositions, and shapes to help facilitate any future generalizations regarding size thresholds in the regulatory context. There are only a few studies specifically designed for toxicological assessment (e.g., dose, duration, frequency of exposure, mechanisms of action). Many of the studies, from which QD toxicity information is derived, it has been cited in reference to it were performed by nanotechnology researchers rather than toxicologists or health scientists. It is therefore difficult to extrapolate the results of such studies in order to reach any conclusions regarding the health and safety of QDs. Nonetheless, these studies may provide important insights that will be useful in guiding the eventual design of standardized toxicity tests and protocols.

The wealth of data accumulated from QD toxicity studies is an invaluable asset that should be exploited to design appropriate methodologies to further assess the toxicity of novel QDs. Researchers often neglect to carry out a comprehensive characterization of QDs prior to using them. In our opinion, this step is absolutely necessary, especially before any toxicity screening is started, precisely because the exact property or properties of QDs responsible for said toxicity are still poorly understood. This omission is one of the reasons behind the current state of confusion surrounding this issue. As epigenetic changes may lead to long-term reprogramming of gene expression long after the initial insult has been removed, results from "nanoepigenetic" assessments may have important implications on the future use of new 
nanomaterials in bioimaging and therapeutic applications. They should be evaluated early in the development of new QDs as well as QD-based devices and clinical tools. Future QD toxicity studies should be standardized and systematized because methodological variability in the current body of literature makes it difficult to compare and contrast results. We advocate the following steps for consistent, comparable toxicology data: (a) standardize dose metrics, (b) characterize QD uptake concentration, (c) identify in vitro models that reflect how the QDs QDs interact with cells in vivo, and (d) use multiple assays to determine sublethal toxicity and biocompatibility. Proceeding without careful evaluation of these critical areas will blunt the progress of nanomedicine and place human health at risk. However, judicious further research into these areas will undoubtedly contribute to development of nanopharmaceuticals for cancer treatment and drug delivery that have minimal to low risk and can highly benefit public health.

\section{Conclusion}

Cadmium-containing QDs are leading the way toward new preparations that can overcome the fundamental limitations of simple free drug formulations, providing the means to change their pharmacological properties and also understand their biological fate in great detail. However, ADME properties depend on multiple factors derived from both inherent physicochemical properties and environmental conditions. The findings also suggest that, under certain conditions, QDs may pose risks to human health, as determined by rodent animal models and in vitro cell cultures. This review outlined the unique features that make QDs an ideal platform for nanocarrier design and discussed how this model has been applied to study vehicle behavior for diverse drug delivery applications. However, it is clear that to make such a goal feasible and relatively risk-free for human beings, more extensive pharmacological and toxicological research of QDs are needed.

\section{Author details}

Lourdes Rodriguez-Fragoso ${ }^{1^{*}}$, Ivonne Gutiérrez-Sancha ${ }^{1}$, Patricia Rodríguez-Fragoso ${ }^{2}$, Anahí Rodríguez-López ${ }^{1}$ and Jorge Reyes-Esparza ${ }^{1}$

*Address all correspondence to: mrodriguezf@uaem.mx

1 Facultad de Farmacia, Universidad Autónoma del Estado de Morelos, Morelos, Mexico

2 Departamento de Física, CINVESTAV-I.P.N Apartado, México 


\section{References}

[1] Fortina P., Kricka LJ., Surrey S., Grodzinski P. Nanobiotechnology: the promise and reality of new approaches to molecular recognition. Trends in biotechnology. 2006. p168-173.

[2] Moghimi SM., Hunter AC., Murray JC. Nanomedicine: current status and future prospects. FASEB J. 2005. p311-330

[3] Rosenblum LT., Kosaka N., Mitsunaga M., Choyke PL., Kobayashi H. In vivo molecular imaging using nanomaterials: general in vivo characteristics of nano-sized reagents and applications for cancer diagnosis. Molecular membrane biology. 2010. p274-285

[4] Aswathy RG., Yoshida Y., Maekawa T., Kumar DS. Near-infrared quantum dots for deep tissue imaging. Analytical and bioanalytical chemistry. 2010. p1417-1435

[5] Madani SY., Shabani F., Dwek MV., Seifalian AM. Conjugation of quantum dots on carbon nanotubes for medical diagnosis and treatmen. International journal of nanomedicine. 2013. p941-950.

[6] Jain KK., The role of nanobiotechnology in drug discovery. Drug Discovery Today. 2005. p1435-442.

[7] Tejada-Berges T., Granai CO., Gordinier M., Gajewski W. Caelyx/Doxil for the treatment of metastatic ovarian and breast cancer. Expert review of anticancer therapy. 2002. p143-150

[8] Gradishar WJ. Albumin-bound paclitaxel: A next-generation taxane. Expert opinion on pharmacotherapy. 2006. p1041-1053

[9] $\mathrm{Mo}^{\circ}$ schwitzer J., Muller RH. New method for the effective production of ultrafine drug nanocrystals. Journal of nanoscience and nanotechnology. 2006. p3145-3153

[10] Schek RM., Hollister SJ., Krebsbach PH. Delivery and protection of adenoviruses using biocompatible hydrogels for localized gene therapy. Molecular therapy: the journal of the American Society of Gene Therapy. 2004. p130-138

[11] Duncan R., Spreafico F. Polymer conjugates. Pharmacokinetic considerations for design and development. Clinical pharmacokinetics. 1994. p290-306.

[12] LaVan DA., Lynn DM., Langer R. Moving smaller in drug discovery and delivery. Nature Reviews Drug Discovery. 2002. p77-84.

[13] Duncan R. The dawning era of polymer therapeutics. Nature Reviews Drug Discovery. 2003. p347-360. 
[14] De Mel A., Oh JT., Ramesh B., Seifalian AM. Biofunctionalized quantum dots for live monitoring of stem cells: applications in regenerative medicine. Regenerative medicine. 2012. p335-347.

[15] Grattoni A., Tasciotti E., Fine D., Fernandez-Moure J.S., Sakamoto J., Hu Y., Weiner B., Ferrari M., Parazynski S. Nanotechnologies and regenerative medical approaches for space and terrestrial medicine. Aviation, space, and environmental medicine. 2012. p1025-1036.

[16] Kingham E., Oreffo RO. Embryonic and induced pluripotent stem cells: understanding, creating, and exploiting the nano-niche for regenerative medicine. ACS Nano. 2013. p1867-1881.

[17] Anto VE., Gomes ME., Mano JF., Reis R.L. From nano-to macro-scale: nanotechnology approaches for spatially controlled delivery of bioactive factors for bone and cartilage engineering. Nanomedicine (Lond). 2012. p1045-1066.

[18] Yaghini E., Seifalian AM., MacRobert AJ. Quantum dots and their potential biomedical applications in photosensitization for photodynamic therapy. Nanomedicine (Lond). 2009. p353-363

[19] Mansur HS. Quantum dots and nanocomposites. Wiley Interdisciplinary Reviews: Nanomedicine and Nanobiotechnology. 2010. p113-129.

[20] Ghasemi Y., Peymani P., Afifi S. Quantum dot: magic nanoparticle for imaging, detection and targeting. Acta Biomedica. 2009. p156-165.

[21] Bruchez M., Moronne M., Gin P., Weiss S., Alivisatos P. The use of nanocrystals in biological detection. Nature Biotechnology. 2004. p47-52.

[22] Baker M. Nanotechnology imaging probes: smaller and more stable. Nature Methods. 2010. p957-962.

[23] Smith AM., Duan H., Mohs AM., Nie S. Bioconjugated quantum dots for in vivo molecular and cellular imaging. Advanced Drug Delivery reviews. 2008. p1226-1240.

[24] Geszke-Moritz M., Moritz M. Quantum dots as versatile probes in medical sciences: synthesis, modification and properties. Materials Science and Engineering: C. 2013. p1008-1021.

[25] Derfus AM., Chan WCW., Bhatia SA. Probing the cytotoxicity of semiconductor quantum dots. Nano Letters. 2004. p4-11.

[26] Bottrill M., Green M. Some aspects of quantum dot toxicity. Chemical Communications, 2011. p7039-7050

[27] Rzigalinski BA., Strobl JS. Cadmium-containing nanoparticles: perspectives on pharmacology and toxicology of quantum dots. Toxicology and applied pharmacology. 2009. p280-288 
[28] Chan WCW., Maxwell DJ., Gao X., Bailey RE., Han M., Nie S. Luminescent quantum dots for multiplexed biological detection and imaging. Current Opinion in Biotechnology. 2002. p40-46.

[29] Piotrowska H., Geszke-Moritz M., Murias M., Balan L., Moritz M., Lulek, J., Schneider R. Thioglycerol-capped Mn-doped ZnS quantum dot bioconjugates as efficient two-photon fluorescent nano-probes for bioimaging. Journal of Materials Chemistry B. 2013. p698-706.

[30] Rzigalinski BA., Meehan K., Davis RM., Xu Y., Miles WC., Cohen CA. Radical Nanomedicine. Nanomedicine. 2006. p339-412.

[31] Li KG., Chen JT., Bai SS., Wen X., Song SY., Yu Q., Wang YQ. Intracellular oxidative stress and cadmium ions release induce cytotoxicity of unmodified cadmium sulfide quantum dots. Toxicology in Vitro. 2009. p1007-1013.

[32] Nan C., Yao H, Yuanyuan S, Xiaoming L., Qing H., Haifeng W., Xiangzhi Z., Renzhong T., Chunhai F. The cytotoxicity of cadmium-based quantum dots. Biomaterials. 2012. p1238-1244.

[33] Mailander V., Landfester K. Interaction of nanoparticles with cells. Biomacromolecules. 2009. p2379-2400.

[34] Godt J., Scheidig F., Grosse-Siestrup C., Esche V., Brandenburg P., Reich A., Groneberg DA., The Toxicity of Cadmium and Resulting Hazards for Human Health. Journal of Occupational Medicine and Toxicology. 2006. p1-6.

[35] Shiohara A., Hoshino A., Hanaki K., Suzuki K., Yamamoto K. On the cyto-toxicity caused by quantum dots. Microbiology and Immunology. 2004. p669-675.

[36] Kloepfer JA., Mielke RE., Wong MS., Nealson KH., Stucky G., Nadeau JL. Quantum dots as strain-and metabolism-specific microbiological labels. Applied and environmental microbiology. 2003. p4205-4213.

[37] Ipe BI., Lehnig M., Niemeyer CM. On the Generation of Free Radical Species from Quantum Dots. Small. 2005. p706-709.

[38] Choi AO., Brown SE., Szyf M., Maysinger D. Quantum Dot-Induced Epigenetic and Genotoxic Changes in Human Breast Cancer Cells. Journal of Molecular Medicine, 2008. p291-302

[39] Raveendran P., Fu J., Wallen S. Completely "green" synthesis and stabilization of metal nanoparticles. Journal of the American Chemical Society. 2003. p13940-13941

[40] Rodriguez P., Muñoz N., San-Martın E., Gonzalez de la Cruz G., Tomas SA., Zelaya A. Synthesis and spectral properties of starch capped CdS nanoparticles in aqueous solution. Journal of crystal growth. 2008. p160-164.

[41] Hossain Z., Huq F. Studies on the interaction between $\mathrm{Cd}(2+)$ ions and nucleobases and nucleotides. J Inorg Biochem 2002. p97-105. 
[42] Rodríguez-Fragoso P., Reyes-Esparza J., León-Buitimea A., Rodríguez-Fragoso L. Synthesis, characterization and toxicological evaluation of maltodextrin capped cadmium sulfide nanoparticles in human cell lines and chicken embryos. Journal of Nanobiotechnology 2012. p1-11.

[43] Williams DF. On the mechanisms of biocompatibility. Biomaterials. 2008. p2941-2953

[44] Zhang Y., Clapp A. Overview of Stabilizing Ligands for Biocompatible Quantum Dot Nanocrystals. Sensor 2011. p11036-11055.

[45] Smith AM., Nie S. Semiconductor nanocrystals: structure, properties, and band gap engineering. Accounts of Chemical Research. 2010. p190-200.

[46] Sandra J., Jerry C., Oleg K., James R., Tomlinson ID., Biocompatible Quantum Dots for Biological Applications. Chemistry Biology Journal. 201. p10-24

[47] Lin Z., Su X., Mu Y., Jin Q. Methods for labeling quantum dots to biomolecules. Journal of nanoscience and nanotechnology. 2004. p641-645.

[48] Clarke SJ., Hollmann CA., Aldaye FA., Nadeau JL. Effect of ligand density on the spectral, physical, and biological characteristics of CdSe/ZnS quantum dots. Bioconjugate Chemistry. 2008. p562-568

[49] Lyer G., Xu J., Weiss S. Single-step conjugation of antibodies to quantum dots for labelling cell surface receptors in mammalian cells. Methods in Molecular Biology. 2011. p553-563

[50] Tamer MS., Azzazy HM., Mansour MM., Kazmierczak SC. Quantum Dots: Heralding a Brighter Future for Clinical Diagnostics. Nanomedicine. 2012. p1755-1769

[51] Zeng Q., Zhang Y., Song K., Kong X., Aalders MC., Zhang H. Enhancement of sensitivity and specificity of the fluoroimmunoassay of hepatitis B virus surface antigen through "flexible" coupling between quantum dots and antibody. Talanta. 2009. p307-312

[52] Luo Y., Zhang B., Chen M., Jiang T., Zhou D., Huang J., Fu W. Sensitive and rapid quantification of C-reactive protein using quantum dot-labeled microplate immunoassay. Journal of Translational Medicine. 2012. p10-24.

[53] Sapsford KE., Spindel S., Jennings T., Tao G., Triulzi RC., Algar WR., Medintz, IL. Optimizing two-color semiconductor nanocrystal immunoassays in single well microtiter plate formats. Sensors. 2011. p7879-7891

[54] Cao Z., Li H., Lau C., Zhang Y. Cross-talk-free simultaneous fluoroimmunoassay of two biomarkers based on dual-color quantum dots. Analytica chimica acta 2011. p44-50

[55] Pinaud F., King D., Moore HP., Weiss S. Bioactivation and cell targeting of semiconductor CdSe/ZnS nanocrystals with phytochelatin-related peptides. Journal of the American Chemical Society. 2004. p6115-6123. 
[56] Cai W., Shin DW., Chen K., Gheysens O., Cao Q., Wang SX., Gambhir SS., Chen X. Peptide-labeled near-infrared quantum dots for imaging tumor vasculature in living subjects. Nano Letters. 2006. p669-676

[57] Orndorff RL., Rosenthal SJ. Neurotoxin quantum dot conjugates detect endogenous targets expressed in live cancer cells. Nano Letters. 2009. p2589-2599

[58] Chopra A. ZW800-1, a zwitterionic near-infrared fluorophore, and its cyclic RGD peptide derivative cyclo-(RGDyK)-ZW800-1. Molecular Imaging and Contrast Agent Database (MICAD) [Internet]. Bethesda (MD): National Center for Biotechnology Information (US). 2004-2013.

[59] Orndorff RL., Warnement MR., Mason JN., Blakely RD., Rosenthal SJ. Quantum dot ex vivo labeling of neuromuscular synapses. Nano Letters. 2008. p780-785

[60] Medintz IL., Uyeda HT., Goldman ER., Mattoussi H. Quantum dot bioconjugates for imaging, labelling and sensing. Natute Materials.2005. p435-446

[61] Bharali DJ., Lucey DW., Jayakumar H., Pudavar HE., Prasad PN. Folate-receptormediated delivery of InP quantum dots for bioimaging using confocal and two-photon microscopy. Journal of the American Chemical Society. 2005. p11364-11371.

[62] Danglot L., Chaineau M., Dahan M., Gendron MC., Boggetto N., Perez F., Galli T. Role of TI-VAMP and CD82 in EGFR cell-surface dynamics and signaling. Journal Cell Science. 2010. p723-735.

[63] Geng L., Zhang HL., Peng H. The formation of acetylcholine receptor clusters visualized with quantum dots. BMC Neuroscience. 2009. P10-80.

[64] Gonda K., Watanabe TM., Ohuchi N., Higuchi H. In vivo nano-imaging of membrane dynamics in metastatic tumor cells using quantum dots. The Journal of biological chemistry. 2010. p2750-2757.

[65] Hikage M., Gonda K., Takeda M., Kamei T., Kobayashi M., Kumasaka M., Ohuchi N. Nano-imaging of the lymph network structure with quantum dots. Nanotechnology. 2010. p185103-185111.

[66] Parak WJ., Gerion D., Zanchet D., Woerz AS., Pellegrino T., Micheel C., Alivisatos AP. Conjugation of DNA to silanized colloidal semiconductor nanocrystalline quantum dots. Chemistry of Materials. 2002. p2113-2119.

[67] Wang AZ., Langer R., Farokhzad OC. Nanoparticle delivery of cancer drugs. Annual review of medicine. 2012. p185-198.

[68] Weng KC., Noble CO., Papahadjopoulos-Sternberg B., Chen FF., Drummond DC., Kirpotin DB., Park JW. Targeted tumor cell internalization and imaging of multifunctional quantum dot-conjugated immunoliposomes in vitro and in vivo. Nano letters, 2008. p2851-2857. 
[69] Dey NS., RAO M. Quantum dot: Novel carrier for drug delivery. International Journal of Research in Pharmaceutical and Biomedical Sciences. 2011. p448-458.

[70] Manabe N., Hoshino A., Liang YQ., Goto T., Kato N., Yamamoto S. Quantum dot as a drug tracer in vivo. NanoBioscience, IEEE Transactions on. 2006. p263-267

[71] Bagalkot V., Zhang L., Levy-Nissenbaum E., Jon S., Kantoff PW., Langer R., Farokhzad OC. Quantum dot-aptamer conjugates for synchronous cancer imaging, therapy, and sensing of drug delivery based on bi-fluorescence resonance energy transfer. Nano Letters. 2007. p3065-3070

[72] Levy-Nissenbaum E., Radovic-Moreno AF., Wang AZ. Langer R., Farokhzad OC. Nanotechnology and aptamers: applications in drug delivery. Trends in Biotechnology. 2008. p442-449

[73] Chakravarthy KV., Davidson BA., Helinski JD., Ding H., Law WC., Yong KT., Knight PR. Doxorubicin-conjugated quantum dots to target alveolar macrophages and inflammation. Nanomedicine: Nanotechnology, Biology, and Medicine. 2011. p88-96

[74] Derfus AM., Chen AA., Min DH., Ruoslahti E., Bhatia SN. Targeted quantum dot conjugates for siRNA delivery. Bioconjugate chemistry. 2007. p1391-1396.

[75] Lifeng Q., Xiaohu G. Emerging application of quantum dots for drug delivery and therapy. Expert Opinion on Drug Delivery. 2008. p263-267.

[76] Fischer HC., Liu LC., Pang KS., Chan, WCW. Pharmacokinetics of nanoscale quantum dots: In vivo distribution, sequestration, and clearance in the rat. Advanced Functional Materials. 2006. p1299-1305.

[77] Kulvietis V., Zurauskas E., Rotomskis R. Distribution of polyethylene glycol coated quantum dots in mice skin Experimengtal Dermatology. 2013. P141-159.

[78] Seto JE., Polat BE., Lopez RF., Blankschtein D., Langer R. Effects of ultrasound and sodium lauryl sulfate on the transdermal delivery of hydrophilic permeants: Comparative in vitro studies with full-thickness and split-thickness pig and human skin. Journal of controlled release: official journal of the Controlled Release Society. 2010. p26-32

[79] Robe A., Pic E., Lassalle HP., Bezdetnaya L., Guillemin F., Marchal F. Quantum dots in axillary lymph node mapping: biodistribution study in healthy mice. BMC Cancer 2008. p111-120.

[80] Kosaka N., Ogawa M., Sato N., Choyke PL., Kobayashi H. In vivo real-time, multicolor, quantum dot lymphatic imaging. The Journal of investigative dermatology. 2009. p2818-2822.

[81] Kulvietis V., Zurauskas E., Rotomskis R. Distribution of polyethylene glycol coated quantum dots in mice skin. Experimental Dermatology, 2013. p141-159 
[82] Tsung-Rong K., Chia-Feng L., Sung-Jan L., Chen-Yuan D., Chia-Chun C., Hsin-Yuan T. Studies of Intracorneal Distribution and Cytotoxicity of Quantum Dots: Risk Assessment of Eye Exposure. ChemIcal Research in toxicology. 2011. p253-261

[83] Schipper ML., Iyer G., Koh AL., Cheng Z., Ebenstein Y., Aharoni A., Keren S., Bentolila LA., Li J., Rao J., Chen X., Banin U., Wu AM., Sinclair R., Weiss S., Gambhir SS. Particle size, surface coating, and PEGylation influence the biodistribution of quantum dots in living mice. Small. 2009. p126-134.

[84] Fubini B., Ghiazza M., Fenoglio I. Physico-chemical features of engineered nanoparticles relevant to their toxicity. Nanotoxicology. 2010. p347-363

[85] Choi HS., Ashitate Y., Lee JH., Kim SH., Matsui A., Insin N., Bawendi MG., SemmlerBehnke M., Frangioni JV., Tsuda A. Rapid translocation of nanoparticles from the lung airspaces to the body. Nature biotechnology. 2010. p1300-1303.

[86] Kreyling WG., Semmler-Behnke M., Takenaka S., Moller W. Differences in the Biokinetics of Inhaled Nano-versus Micrometer-Sized Particles. Accounts of chemical research. 2013. p714-722.

[87] Jani P., Halbert GW., Langridge J., Florence AT. Nanoparticle uptake by the rat gastrointestinal mucosa: quantitation and particle size dependency. The Journal of pharmacy and pharmacology. 1990. p821-826.

[88] Hillyer JF., Albrecht RM. Gastrointestinal persorption and tissue distribution of differently sized colloidal gold nanoparticles. Journal of pharmaceutical sciences. 2001. p1927-1936.

[89] Florence AT: Nanoparticle uptake by the oral route: fulfilling its potential? Drug Discovery Today: Technologies 2005. p75-81.

[90] Schleh C., Semmler-Behnke M., Lipka J., Wenk A., Hirn S., Schaffler M., Schmid G., Simon U., Kreyling WG. Size and surface charge of gold nanoparticles determine absorption across intestinal barriers and accumulation in secondary target organs after oral administration. Nanotoxicology. 2012. p36-46.

[91] Klement P., Du YJ., Berry L., Andrew M., Chan AKC. Blood-compatible biomaterials by surface coating with a novel antithrombin-heparin covalent complex. Biomaterials. 2002. p527-535.

[92] Dobrovolskaia M.A., Mcneil S.E. Immunological properties of engineered nanomaterials. Nature nanotechnology. 2007. p469-478.

[93] Fischer HC., Liu L., Pang KS., Chan WCW. Pharmacokinetics of Nanoscale Quantum Dots: In Vivo Distribution, Sequestration, and Clearance in the Rat. Advanced Functional Materials. 2006. p1299-1305. 
[94] Gopee NV., Roberts DW., Webb P., Cozart CR., Siitonen PH., Warbritton AR., Yu WW., Colvin VL., Walker NJ., Howard PC. Migration of intradermally injected quantum dots to sentinel organs in mice. Toxicology Science. 2007. p249-257.

[95] Yang RS., Chang LW., Wu JP., Tsai MH., Wang HJ., Kuo YC., Yeh TK., Yang CS., Lin P., Persistent tissue kinetics and redistribution of nanoparticles, quantum dot 705 , in mice: ICP-MS quantitative assessment. Environmental health perspectives. 2007. p1339-1343.

[96] Pelley, JL., Daar AS., Saner MA. State of academic knowledge on toxicity and biological fate of quantum dots. Toxicological Sciences. 2009. p276-296.

[97] Kim J., Kim KS., Jiang G., Kang H., Kim S., Kim BS., Park MH., Hahn, SK. In vivo real-time bioimaging of hyaluronic acid derivatives using quantum dots. Biopolymers. 2008. p1144-1153.

[98] Ballou B., Lagerholm BC., Ernst LA., Bruchez MP., Waggoner AS. Noninvasive imaging of quantum dots in mice. Bioconjugate chemistry. 2004. p79-86.

[99] Salykina YF., Zherdeva VV., Dezhurov SV., Wakstein MS., Shirmanova MV., Zagaynova EV., Savitsky AP. Biodistribution and clearance of quantum dots in small animals. In Sartov Fall Meeting. International Society for Optics and Photonics. 2010. p799908-799908.

[100] TsingHai W., HuiAn H., YiKong H., ChiShiun C., YuhChang S., ChuFang W. The in vivo biodistribution and fate of CdSe quantum dots in the murine model: a laser ablation inductively coupled plasma mass spectrometry study. Analytical and bioanalytical chemistry. 2012. p3025-3036.

[101] Wu X., Tian F., Zhao JX., Wu M. Evaluating pharmacokinetics and toxicity of luminescent quantum dots. Expert Opinion on Drug Metabolism \& Toxicology. 2013. p1265-1277.

[102] Su Y., Peng F., Jiang Z., Zhong Y., Lu Y., Jiang X., Huang Q., Fan C., Lee ST., He Y. In vivo distribution, pharmacokinetics, and toxicity of aqueous synthesized cadmiumcontaining quantum dots. Biomaterials. 2011. p5855-5862.

[103] Weiss N., Miller F., Cazaubon S., Couraud PO. The blood-brain barrier in brain homeostasis and neurological diseases. Biochimica et biophysica acta. 2009. p842-857.

[104] Lipinski, CA. Drug-like properties and the causes of poor solubility and poor permeability. Journal of pharmacological and toxicological methods. 2000. p235-249.

[105] Kato S., Itoh K., Yaoi T., Tozawa T., Yoshikawa Y., Yasui H., Kanamura N., Hoshino A., Manabe N., Yamamoto K., Fushiki S. Organ distribution of quantum dots after intraperitoneal administration, with special reference to area-specific distribution in the brain. Nanotechnology. 2010. p335103-335110 
[106] Xu G., Yog KT., Roy I., Mahajan SD., Ding H., Schwartz, SA., Prasad PN. Bioconjugated quantum rods as targeted probes for efficient transmigration across an in vitro blood-brain barrier. Bioconjugate chemistry. 2008. p1179-1185.

[107] Xu G., Mahajan S., Roy I., Yong KT. Theranostic quantum dots for crossing bloodbrain barrier in vitro and providing therapy of HIV-associated encephalopathy. Frontier in Pharmacology. 2013. p1-8

[108] Brendel K, Duhamel RC, Shepard TH. Embryotoxic drugs. Biological research in pregnancy and perinatology. 1985. p1-54.

[109] Chan WH., Shiao NH. Cytotoxic effect of CdSe quantum dots on mouse embryonic development. Acta Pharmacologica. 2008. p259-266

[110] Chu M., Wu Q., Yang H., Yuan R., Hou S., Yang Y., Sheng L. Transfer of quantum dots from pregnant mice to pups across the placental barrier. Small. 2010. p670-678.

[111] Wick P., Malek A., Manser P., Meili D., Maeder-Althaus X., Diener L. Barrier capacity of human placenta for nano-sized materials. Environmental Health Perspectives. 2010. p432-436.

[112] Žalgevičienè V., Kulvietis V., Bulotienè D., Didžiapetrienė J., \& Rotomskis R. The effect of nanoparticles in Rats During Critical periods of pregnancy. Medicina (Kaunas). 2012. p256-64.

[113] Yamashita K., Yoshioka Y., Higashisaka K., Mimura K., Morishita Y., Nozaki Ml. Silica and titanium dioxide nanoparticles cause pregnancy complications in mice. Nature Nanotechnology. 2011. p321-328.

[114] Wick P., Malek A., Manser P., Meili D., Maeder-Althaus X., Diener L. Barrier capacity of human placenta for nano-sized materials. Environmental Health Perspective. 2010. p432-436.

[115] Nel A., Xia T., Madler L., Li N. Toxic potential of materials at the nanolevel. Science. 2006. p622-627.

[116] Chen Z., Chen H., Meng H., Xing G., Gao X., Sun B., Fang X. Bio-distribution and metabolic paths of silica coated CdSeS quantum dots. Toxicology and Applied Pharmacology. 2008. p364-371

[117] Yang RS., Chang LW., Wu JP., Tsai MH., Wang HJ., Kuo YC., Yeh TK., Yang CS., Lin P. Persistent tissue kinetics and redistribution of nanoparticles, quantum dot 705, in mice: ICP-MS quantitative assessment. Environmental Health Perspectives. 2007. p1339-1343.

[118] Vibin M., Vinayakan R., John A., Raji V., Rejiya CS., Abraham A. Biokinetics and In vivo Distribution Behaviours of Silica-Coated Cadmium Selenide Quantum Dots. Biological trace element research. 2011. p213-222 
[119] Hoshino A., Fujioka K., Oku T., Suga M., Sasaki T., Ohta M., Yasuhara K., Suzuki K., Yamamoto K. Physicochemical properties and cellular toxicity of nanocrystal quantum dots depend on their surface modifications. Nano Letters. 2004. p2163-2169.

[120] Lovrić J., Bazzi HS., Cuie Y., Fortin GR., Winnik FM., Maysinger D. Differences in subcellular distribution and toxicity of Green and red emitting CdTe quantum dots. Journal of Molecular Medicine. 2005. p377-385

[121] Mahto, SK., Park C., Yoon TH., \&-Rhee SW. Assessment of cytocompatibility of surface-modified CdSe/ZnSe quantum dots for BALB/3T3 fibroblast cells. Toxicology in vitro. 2010. p1070-1077.

[122] Zhang B., Wang X., Liu F., Cheng Y., Shi D. Effective reduction of nonspecific binding by surface engineering of quantum dots with bovine serum albumin for cell-targeted imaging. Langmuir. 2012. p16605-16613.

[123] Cho SJ., Maysinger D., Jain M., Röder B., Hackbarth S., Winnik FM. Long-term exposure to CdTe quantum dots causes functional impairments in live cells. Langmuir. 2007. p1974-1980.

[124] Yuan T., Songling H., Hongmei L., Xin C., Li-Huang L., Jianxiang Z. The role of surface chemistry in determining in vivo biodistribution. Biomaterials. 2013. p8741-8755.

[125] Zheng X., Tian J., Weng L., Wu L., Jin Q., Zhao J., Wang L.. Cytotoxicity of cadmiumcontaining quantum dots based on a study using a microfluidic chip. Nanotechnology. 2012. p055102-055111.

[126] Ryman-Rasmussen J. P., Riviere J. E., Monteiro-Riviere N. A. Surface Coatings Determine Cytotoxicity and Irritation Potential of Quantum Dot Nanoparticles in Epidermal Keratinocytes. Journal of Investigative Dermatology. 2007. p143-153.

[127] Chen N., He Y., Su Y., Li X., Huang Q., Wang H., Fan C. The cytotoxicity of cadmium-based quantum dots. Biomaterials. 2012. p1238-1244.

[128] Su Y., Hu M., Fan C., He Y., Li Q., Li W., Huang Q. The cytotoxicity of CdTe quantum dots and the relative contributions from released cadmium ions and nanoparticle properties. Biomaterials. 2010. p4829-4834.

[129] Soenen SJ., Demeester J., De Smedt SC., Braeckmans K. The cytotoxic effects of polymer-coated quantum dots and restrictions for live cell applications. Biomaterials. 2012. p4882-4888.

[130] Bao YJ., Li JJ., Wang YT., Yu L., Lou L., Du WJ., Zhu JZ. Probing cytotoxicity of CdSe and CdSe/CdS quantum dots. Chinese Chemical Letters. 2011. p843-846.

[131] Li S., Wang Y., Wang H., Bai Y., Liang G., Wang Y., Xiao Z. MicroRNAs as participants in cytotoxicity of CdTe quantum dots in NIH/3T3 cells. Biomaterials. 2011. p3807-3814.

[132] Roberts JR., Antonini JM., Porter DW., Chapman RS., Scabilloni JF., Young SH., Mercer RR. Lung toxicity and biodistribution of $\mathrm{Cd} / \mathrm{Se}-\mathrm{ZnS}$ quantum dots with different 
surface functionalgroups after pulmonary exposure in rats. Particle and Fibre Toxicology. 2013. p1-17.

[133] Yang RH., Chang LW., Wu JP., Tsai MH., Wang HJ., Kuo YC., Yeh TK., Yang CS., Lin P. Persistent tissue kinetics and redistribution of nanoparticles, quantum dot705, in mice: ICP-MS quantitative assessment. Environmental health perspectives. 2007. p1339-1343.

[134] Fischer H., Liu L., Pang KS., Chan W. Pharmacokinetics of nanoscale quantum dots: in vivo distribution, sequestration, and clearance in the rat. Advanced Functional Materials. 2006. p1299-1305.

[135] Geys J., Nemmar A., Verbeken E., Smolders E., Ratoi M., Hoylaerts MF., Hoet PH. Acute Toxicity and Prothrombotic Effects of Quantum Dots: Impact of Surface Charge. Environmental Health Perspectives. 2008. p1607-1613.

[136] Gagné F., Auclair J., Turcotte P., Fournier M., Gagnon C., Sauve S., Blaise C. Ecotoxicity of CdTe quantum dots to freshwater mussels: Impacts on immune system, oxidative stress and genotoxicity. Aquatic Toxicology. 2008. p333-340.

[137] Wiecinski PN., Metz KM., King-Heiden TC., Louis KM., Mangham AN., Hamers RJ., Pedersen JA. Toxicity of Oxidatively Degraded Quantum Dots to Developing Zebrafish (Danio rerio). Environmental science \& technology. 2013. p9132-9139.

[138] Li KG., Chen JT., Bai SS., Wen X., Song SY., Yu Q., Wang YQ. Intracellular oxidative stress and cadmium ions release induce cytotoxicity of unmodified cadmium sulfide quantum dots. Toxicology in Vitro. 2009. p1007-1013. 
